\title{
PRODUÇÃO E QUALIDADE DA COUVE FLOR EM FUNÇÃO DE DOSES DE BORO NA REGIÃO AMAZÔNICA
}

Silvana Ramlow Otto Teixeira da Luz ${ }^{1}$; Jhonny Kelvin Dias Martins ${ }^{1}$; Kênia Barbosa de Sousa"; Edna da Silva Rocha1; Fábio Régis de Souza ${ }^{2}$

${ }^{1}$ Graduando (a) do curso de Agronomia, Fundação Universidade Federal de Rondônia - UNIR (silvanaotto2016@gmail.com) Rolim de Moura, Brasil.

2 Professor Doutor do Departamento de Agronomia, Fundação Universidade Federal de Rondônia - UNIR, Rolim de Moura, Brasil.

Recebido em: 02/10/2017 - Aprovado em: 21/11/2017 - Publicado em: 05/12/2017 DOI: 10.18677/EnciBio_2017B51

O boro é um micronutriente altamente exigido pela couve flor, e apresenta grande influência na qualidade e produção das inflorescências. Diante disso, o objetivo deste trabalho foi avaliar o efeito das doses de boro sobre a produção e a qualidade da couve flor na região amazônica. O experimento foi realizado no Campus experimental da Universidade Federal de Rondônia. O delineamento experimental foi em blocos casualizados, com quatro doses boro $\left(1,2,4,8 \mathrm{~kg} \mathrm{ha}^{-1}\right)$ e quatro repetições. As parcelas foram constituídas de quatro linhas, totalizando $4,5 \mathrm{~m}^{2}$. A área útil foi formada por duas linhas centrais, desconsiderando as plantas de cada extremidade, resultando em quatro plantas por cada unidade experimental. $O$ espaçamento utilizado foi de $0,9 \mathrm{~m}$ entre linhas e $0,5 \mathrm{~m}$ entre plantas. Foram avaliadas as características: diâmetro da inflorescência, massa fresca da inflorescência, produção e classificação em classes e categoria. A aplicação de $4 \mathrm{~kg}$ $\mathrm{ha}^{-1}$ de $\mathrm{B}$ apresentou os melhores resultados para todos as características avaliadas. A aplicação de $1 \mathrm{~kg} \mathrm{ha}^{-1}$ ou de $8 \mathrm{~kg} \mathrm{ha}^{-1}$ de $\mathrm{B}$ apresentou perdas de qualidade das inflorescências.

PALAVRAS-CHAVE: Brassica oleracea var. botrytis, micronutriente, produtividade

\section{PRODUCTION AND QUALITY OF THE FLOWER COUVER IN THE FUNCTION OF DOSES OF BORO IN THE AMAZON REGION}

\begin{abstract}
Boron is a micronutrient highly demanded by cauliflower, and has great influence on the quality and production of inflorescences. Therefore, the objective of this work was to evaluate the effect of boron doses on the production and quality of cauliflower in the Amazon region. The experiment was carried out at the experimental campus of the Federal University of Rondônia. The experimental design was a randomized block with four boron doses $\left(1,2,4,8 \mathrm{~kg} \mathrm{ha}^{-1}\right)$ with four replicates. The plots consisted of four lines, totaling $4.5 \mathrm{~m}^{2}$. The useful area was formed by two central lines, disregarding the plants of each end, resulting in four plants for each experimental unit. The spacing used was $0.9 \mathrm{~m}$ between rows and $0.5 \mathrm{~m}$ between plants. The following characteristics were evaluated: inflorescence diameter, ENCICLOPÉDIA BIOSFERA, Centro Científico Conhecer - Goiânia, v.14 n.26; p. 5312017
\end{abstract}


inflorescence fresh mass, production and classification in classes and category. The application of $4 \mathrm{~kg} \mathrm{ha}^{-1}$ of $\mathrm{B}$ presented the best results for all evaluated characteristics. The application of $1 \mathrm{~kg} \mathrm{ha}^{-1}$ or $8 \mathrm{~kg} \mathrm{ha}^{-1}$ of $B$ presented loss of quality of inflorescences.

KEYWORDS: Brassica oleracea var. Botrytis, micronutrient, productivity

\section{INTRODUÇÃO}

A couve flor (Brassica oleracea var. botrytis), pertencente à família das Brassicáceas (FILGUEIRA, 2013) possui um ciclo variando entre 80 a 130 dias (TORRES et al., 2014a) é uma das hortaliças mais cultivadas no Brasil (FERREIRA et al., 2014), podendo ser cultivada o ano inteiro em praticamente todo o país (FILGUEIRA, 2008) possui alto valor nutritivo o que leva a grande extração de nutrientes do solo (SILVA et al., 2012). De acordo com Fonseca e Hanisch (2015), Torres et al. (2014b) o manejo da adubação e as condições climáticas são os principais fatores que influenciam a produção e a qualidade da couve flor.

As características relacionadas a comercialização como, o tamanho da cabeça e a qualidade, estão ligados aos nutrientes que são absorvidos durante o ciclo da cultura, principalmente do boro (CAMARGO et al., 2008). O boro é um micronutriente altamente exigido pelas Brássicas, e apresenta grande influência sobre a produção (SILVA et al., 2014). Filgueira (2013) recomenda de 2 a $4 \mathrm{~kg} \mathrm{ha-1}$ de boro aplicados no solo e mais 3 a 4 aplicações foliares de $0,2 \%$ de $B$ na solução, para a cultura da couve flor, sem levar em consideração os teores no solo.

Nos solos tropicais o grupo das hortaliças pertencente à família das Brássicas estão as mais exigentes em boro (PIZZETA et al., 2005). Sendo este, um problema comum em condições de campo (CAMARGO et al., 2008), provocando a diminuição dos pontos de crescimento das hortaliças (SILVA et al., 2012). Na couve flor a deficiência de boro induz a ocorrência de anomalia fisiológica, caracterizada pelo aparecimento de medula oca e inflorescência pouco compacta (Filgueira, 2013). Como o transporte do boro na planta ocorre via xilema, estas desordens podem estar relacionadas a sua baixa mobilidade na planta, visto que, a distribuição do boro depende da perda de água pela transpiração dos órgãos das plantas (KAJOI et al., 2009).

Pizzeta et al. (2005) avaliaram a resposta de brócolis, repolho e couve flor em função das doses de boro em solo arenoso e concluiu que a couve flor apresentou resposta quadrática para a produtividade, sendo necessário $5,1 \mathrm{~kg} \mathrm{ha}^{-1}$ para atingir a produtividade máxima de $30 \mathrm{t} \mathrm{ha}^{-1}$, os autores ainda afirmaram, que nos tratamentos sem a aplicação de boro houve uma grande porcentagem de cabeças impróprias para a comercialização e nas doses de 6 e $8 \mathrm{t} \mathrm{ha}^{-1}$ ocorreu a diminuição da produção, caracterizando o efeito fitotóxico do micronutriente na planta.

São poucos os trabalhos encontrados na literatura sobre a adubação mineral da couve flor, principalmente com o micronutriente boro, o que evidencia a necessidade do desenvolvimento de pesquisas voltadas para este tema. Diante disso, o objetivo deste trabalho foi avaliar o efeito das doses de boro sobre a produção e a qualidade da couve flor na região amazônica. 


\section{MATERIAL E MÉTODOS}

O experimento foi instalado no Campus experimental do curso de Agronomia da Universidade Federal de Rondônia (UNIR), localizado no município de Rolim de Moura RO, cujas coordenadas geográficas são 1148'13" de latitude Sul, 6148'12" de longitude oeste e altitude de 290 metros acima do nível do mar. O clima é tropical quente e úmido com estações de seca bem definida (junho a setembro) com chuvas intensas nos meses de novembro a março. A precipitação média atual é de 2.250 $\mathrm{mm}$, umidade relativa do ar elevada, no período chuvoso, em torno de $85 \%$. O solo foi classificado como Latossolo Vermelho-amarelo distrófico. Com as seguintes características químicas: $\mathrm{pH}$ em $\mathrm{H}_{2} \mathrm{O} 6,44 ; \mathrm{M} . \mathrm{O}, 8,36 \mathrm{~g} \mathrm{dm}^{-3} ; \mathrm{P} 1,11 \mathrm{mg} \mathrm{dm}^{-3} ; \mathrm{Na}$

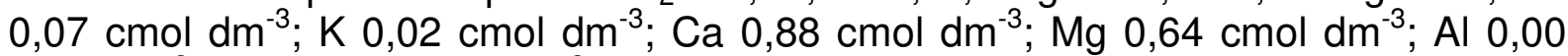
$\mathrm{cmol} \mathrm{dm}^{-3}$; H+Al 3,63 $\mathrm{cmol} \mathrm{dm}^{-3}$; Arg. 21,0\%; Areia 43,88\%.

$O$ delineamento experimental utilizado foi em blocos casualizado, com quatro doses boro $\left(1,2,4,8 \mathrm{~kg} \mathrm{ha}^{-1}\right)$ na forma de Bórax (11\% de B), com 4 repetições, totalizando 16 parcelas experimentais. As parcelas foram constituídas de quatro linhas, totalizando $4,5 \mathrm{~m}^{2}$. A área útil foi formada por duas linhas centrais, desconsiderando as plantas de cada extremidade, resultando em quatro plantas por cada unidade experimental. $\mathrm{O}$ espaçamento utilizado foi de $0,9 \mathrm{~m}$ entre linhas e 0,5 $\mathrm{m}$ entre plantas, totalizando 22.222 plantas por hectare.

Após o preparo do solo realizado de forma convencional através de duas gradagem, foram preparadas as covas de $30 \times 30 \times 30 \mathrm{~cm}$. As adubações de plantio e cobertura seguiram com base na análise de solo e nas recomendações para a cultura, sendo aplicados no plantio $400 \mathrm{~kg}_{\text {de }} \mathrm{P}_{2} \mathrm{O}_{5} \mathrm{ha}^{-1}, 40 \mathrm{~kg}$ de $\mathrm{K}_{2} \mathrm{O} \mathrm{ha}{ }^{-1}, 20 \mathrm{~kg}$ de $\mathrm{N} \mathrm{ha}^{-1}$, na forma de superfosfato triplo, cloreto de potássio e ureia respectivamente, além da adubação borácica que foi realizada de uma única vez na cova de plantio. $\mathrm{Na}$ adubação de cobertura aplicou-se $30 \mathrm{~kg}$ de $\mathrm{K}_{2} \mathrm{O} \mathrm{ha}^{-1}, 20$ DAT (Dias Após o Transplante) adubação nitrogenada foi dividida em 3 vezes $30 \mathrm{~kg} \mathrm{ha}^{-1}, 20$ DAT $30 \mathrm{~kg}$ $\mathrm{ha}^{-1}, 45$ DAT e $20 \mathrm{~kg} \mathrm{ha}^{-1}$ aos 60 DAT.

As mudas utilizadas na implantação do experimento foram produzidas em ambiente protegido. A semeadura foi realizada no dia 03 de abril de 2017 em bandejas de poliestireno expandido com 128 células utilizando o substrato comercial VIVATTO ${ }^{\circledR}$. Aos 25 dias após a semeadura, quando as mudas apresentavam de 4 a 5 folhas verdadeiras, foram transplantadas para o campo. A irrigação foi realizada utilizando um sistema de gotejamento auto compensante, mantendo-se o solo próximo a capacidade de campo. O controle de plantas daninhas foi realizado através de capinas manuais e ao longo do experimento foram realizados todos os tratos culturais necessários para o desenvolvimento das plantas, sendo eles 0 controle de pragas e doenças. Para evitar o bronzeamento das inflorescências, as mesmas foram protegidas com o uso da técnica denominada "amarrio", onde se utilizam as folhas intermediárias para envolver a inflorescência, sendo estas folhas presas com um elástico.

A colheita foi realizada à medida que as inflorescências apresentavam desenvolvimento completo com botões florais ainda unidos, cabeças compactas e firmes. Com início aos 67 (DAT) se estendendo por mais 23 dias. Durante o período de colheita foram realizadas as avaliações de diâmetro da inflorescência (DI), Massa fresca das inflorescências (MFI), produtividade $(P)$ e classificação em classes e categoria de acordo com a Hortibrasil (2009). Para as variáveis quantitativas, foram ajustadas equações de regressão polinomial testando-se 0 modelo linear $e$ 
quadrático e selecionando aquele que apresentou maior coeficiente de determinação com os dados das variáveis.

\section{RESULTADOS E DISCUSSÃO}

O diâmetro das inflorescências e a massa, assim como a produtividade total, tiveram valores médios considerados satisfatórios: $222,6 \mathrm{~mm}, 709,45$ e $19,71 \mathrm{t} \mathrm{ha}^{-1}$ respectivamente. O maior diâmetro da inflorescência foi de $222,6 \mathrm{~mm}$ obtido na dose de $4,44 \mathrm{~kg} \mathrm{ha}^{-1}$ de boro (Figura 1). Silva et al. (2014) realizaram um estudo com a aplicação de doses de boro na cultura do repolho e observaram efeito significativo para diâmetro da cabeça com ponto máximo de $6,8 \mathrm{~kg} \mathrm{ha}^{-1}$ de B. Resultados inferiores ao presente estudo foram encontrados por Zanuzo et al. (2013) que avaliaram o desempenho agronômico de genótipos de couve flor em Sinop e obtiveram no híbrido Veneza o diâmetro de $166 \mathrm{~mm}$. Ao desenvolver um trabalho com doses de nitrogênio na cultura da couve flor Oliveira et al. (2017), obtiveram diâmetros de inflorescências de até $21,52 \mathrm{~cm}$ no híbrido Verona.

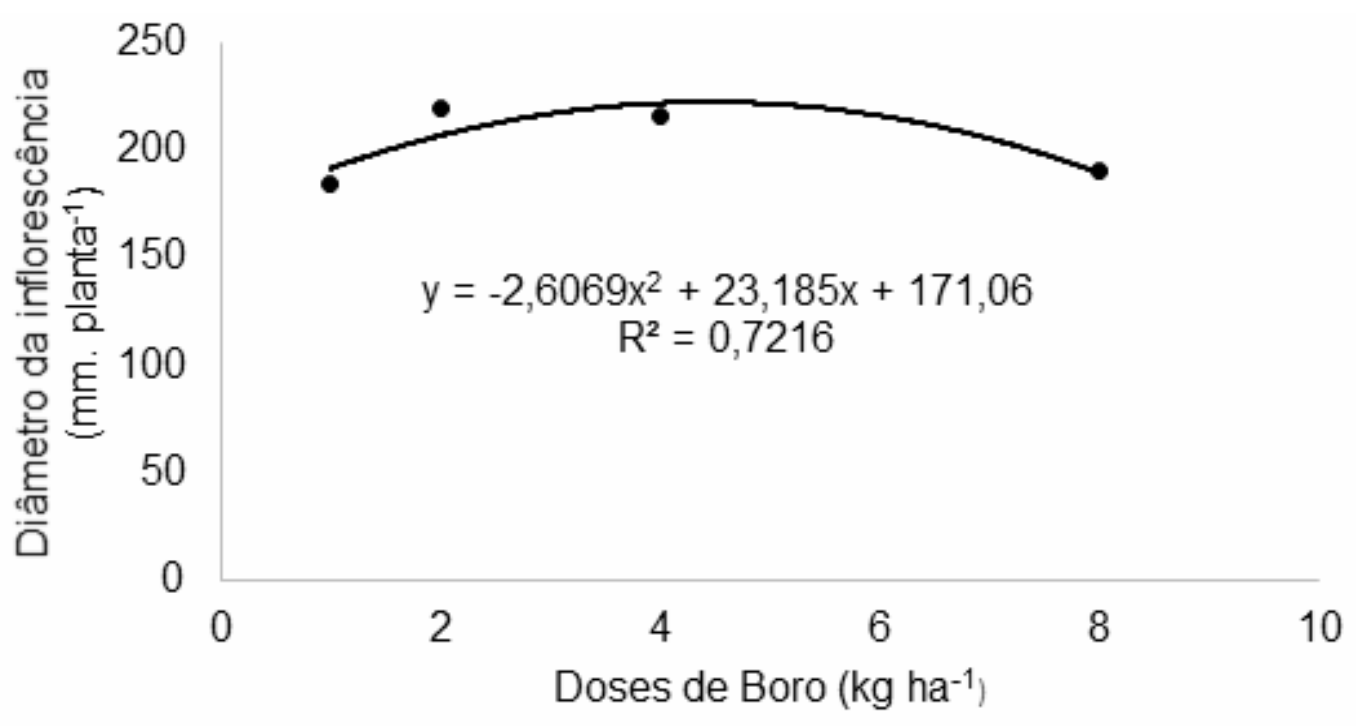

FIGURA 1: Diâmetro da inflorescência $(\mathrm{mm})$ em função das doses de boro $\left(\mathrm{kg} \mathrm{ha}^{-1}\right)$

Com relação a classificação comercial das inflorescências (Tabela 1), pode-se observar que as doses de 2 e $4 \mathrm{~kg} \mathrm{ha}^{-1}$ de $\mathrm{B}$ foram as que apresentaram maiores porcentagens de inflorescências com diâmetro transversal maior ou igual a $230 \mathrm{~mm}$. As inflorescências maiores possuem maior valor comercial, pois são classificadas com um padrão de comercialização superior (HORTIBRASIL, 2009). Torres et al. (2015), avaliaram o desenvolvimento e produtividade de couve flor influenciados por tipos de coberturas no solo e os autores obtiveram diâmetros das inflorescências entre 55,1 e 54,7 cm. 
TABELA 1: Distribuição das classes das inflorescências de couve flor de acordo com o Hortibrasil (2009).

\begin{tabular}{lllllllll}
\hline $\begin{array}{l}\text { Boro kg } \\
\text { ha }^{-1}\end{array}$ & 1 & 2 & 3 & 4 & 5 & 6 & 7 & 8 \\
\hline 1 & 0 & 12,5 & 0 & 0 & 43,75 & 18,75 & 12,5 & 12,5 \\
\hline 2 & 0 & 0 & 0 & 0 & 0 & 25 & 31,25 & 43,75 \\
\hline 4 & 0 & 0 & 0 & 6,25 & 6,25 & 18,75 & 31,25 & 37,5 \\
\hline 8 & 0 & 0 & 0 & 18,75 & 31,25 & 18,75 & 18,75 & 12,5 \\
\hline
\end{tabular}

8= diâmetro da cabeça $>230 \mathrm{~mm} 7=$ diâmetro da cabeça $>210<230 \mathrm{~mm} ; 6=$ diâmetro de cabeça $>190<210 \mathrm{~mm}$; $5=$ diâmetro da cabeça $>170>190 \mathrm{~mm} ; 4=$ diâmetro de cabeça $>150<170 \mathrm{~mm} ; 3=$ diâmetro da cabeça $>130<150 \mathrm{~mm} ; 2=$ diâmetro da cabeça $>100<130 \mathrm{~mm}$;

Assim como o diâmetro da inflorescência, a massa fresca e a produtividade se ajustou ao modelo de regressão quadrática. Na dose de $4,57 \mathrm{~kg} \mathrm{ha}^{-1}$ de boro foi obtido a massa fresca de $709,45 \mathrm{~g}^{\text {. }}$ planta $^{-1}$ (Figura 2A) e produtividade de 19,71 t ha $^{-1}$ (Figura 2B). A massa média da inflorescência representa um importante componente da produção, e também está relacionada com a qualidade do vegetal, pois é uma maneira de exprimir, o tamanho das inflorescências (FERREIRA et al., 2014). Resultado superior, foi encontrado por Zanuzo et al. (2013) para massa fresca, onde foi obtido no híbrido Veneza uma média de 800 g.planta ${ }^{-1}$, entretanto para a produtividade o resultado foi de $16,68 \mathrm{t} \mathrm{ha}^{-1}$, sendo inferior ao do presente estudo. Camargo et al. (2008) não encontraram resultados significativos para massa fresca e produtividade em relação as doses de B.
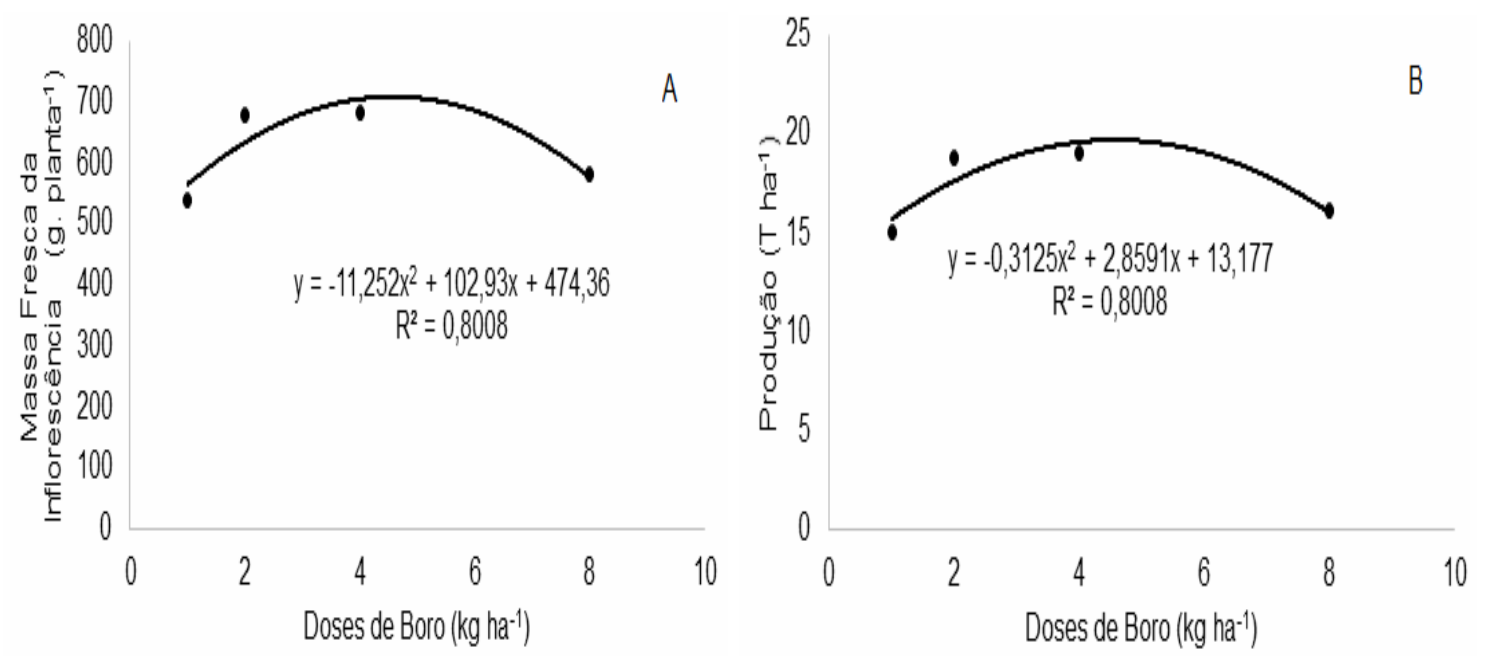

FIGURA 2: Massa fresca da inflorescência (g. planta $\left.{ }^{-1}\right)(A)$ e produção $\left(T\right.$ ha $\left.{ }^{-1}\right)$ em função das doses de Boro $\left(\mathrm{kg} \mathrm{ha}^{-1}\right)$

A dose de $4 \mathrm{~kg} \mathrm{ha}^{-1}$ de boro apresentou inflorescências com melhores qualidades para a comercialização (Tabela 2), em torno de $62,5 \%$ foram 
classificadas como extra. Zanuzo et al. (2013) com a realização de um estudo classificaram o híbrido Veneza na categoria extra.

TABELA 2: Distribuição da categoria das inflorescências de couve flor de acordo com Hortibrasil (2009).

\begin{tabular}{ccccc}
\hline Boro kg ha ${ }^{-1}$ & Extra & I & $\begin{array}{c}\text { Categoria } \\
\text { II } \\
\text { \% inflorescências }\end{array}$ & III \\
\hline 1 & 12,5 & 25 & 18,75 & 43,75 \\
\hline 2 & 31,25 & 31,25 & 18,75 & 12,5 \\
\hline 4 & 62,5 & 25 & 12,5 & 0 \\
\hline 8 & 37,5 & 25 & 18,75 & 18,75 \\
\hline
\end{tabular}

Extra $=$ isentas de defeitos ou dentro da porcentagem aceitável

No tratamento com $1 \mathrm{~kg} \mathrm{ha}^{-1}$ de boro houve uma grande porcentagem de inflorescências com deformação, podridão e medula oca, o que reduz a qualidade das inflorescências, além disso, muitas inflorescências não foram classificadas entre as categorias propostas pela Hortibrasil (2009), visto que, as quantidades de defeitos eram superiores as permitidas para serem incluídas em alguma das categorias. Segundo Kajoi et al. (2009) Pizetta, et al. (2005) as características apresentadas pelas inflorescências na dose de $1 \mathrm{~kg} \mathrm{ha}^{-1}$ de B são sintomas de deficiência do micronutriente.

Com a dose de $8 \mathrm{~kg} \mathrm{ha}^{-1}$ de $\mathrm{B}$ ocorreu a morte de algumas plantas, sendo que houve inflorescências bastante afetadas pela podridão, além disso, também houve uma redução das inflorescências na categoria extra, o que pode indicar efeito fitotóxico do boro. Resultado semelhante ao encontrado por Pizetta et al. (2005), que com as doses de 6 a $8 \mathrm{~kg} \mathrm{ha}^{-1}$ de B apresentou morte das plantas.

\section{CONCLUSÃO}

A dose de $4 \mathrm{~kg} \mathrm{ha}^{-1}$ de boro apresentou os melhores resultados para todas os parâmetros avaliados.

\section{REFERÊNCIAS}

CAMARGO, S.; MELLO, M. C.; FOLTRAN, S.; CAMARGO, D. E.; AUGUSTO, C. Q. Produtividade e podridão parda em couve-flor de inverno influenciadas pelo nitrogênio e boro. Bragantia 67(2):371-375. 2008. Disponível em: < http://dx.doi.org/10.1590/S0006-87052008000200012>. Doi: 10.1590/S000687052008000200012.

FERREIRA, N. C.; SELEGUINI, A.; SENO, S.; FARIA JÚNIOR, M. J. A. Produção e qualidade de inflorescências de couve-flor em função da densidade de plantio. Revista de Agricultura Neotropical, Cassilândia-MS, v. 1, n. 2, p. 1-7, out./dez. 2014. Disponível https://periodicosonline.uems.br/index.php/agrineo/article/view/241>.

em:<

FILGUEIRA, F. A. R. Novo Manual de Olericultura: Agrotecnologia moderna na produção e comercialização de hortaliças. 3ª ed. rev. Viçosa, 421p. 2008. 
FILGUEIRA, F. A. R. Novo Manual de Olericultura: Agrotecnologia moderna na produção e comercialização de hortaliças. Viçosa: UFV, 421p. 2013.

FONSECA, J. A.; HANISCH, A. L. Efeito de Humoativo comercial na produtividade da couve-flor no Estado de Santa Catarina. Revista Verde (Pombal - PB - Brasil) v. 10, n.2, p. 245 - 250, abr-jun, 2015. Disponível em:< http://dx.doi.org/10.18378/rvads.v10i2.2634> Doi: 10.18378/rvads.v10i2.2634.

HORTIBRASIL, Instituto Brasileiro de Qualidade em Horticultura. Normas de Identidade, Padronização e Classificação da Couve-flor 2009. Disponível em: $<$ http://www.hortibrasil.org.br/classificacao/couveflor/couveflor $>$. Acesso em $10 \mathrm{de}$ julho de 2017.

KAJOI, C.; MELLO, S. C.; CAMARGO, M. S.; FAGAN, E. B.; RIBEIRO, M. F. Adubação com nitrogênio e boro na incidência de hastes ocas e na produção de couve-flor. Ciência e agrotecnologia, Lavras, v. 33, n. 1, p. 13-17, jan./fev., 2009. Disponível em: < http://dx.doi.org/10.1590/S1413-70542009000100001>. Doi: 10.1590/S1413-70542009000100001.

OLIVEIRA, F. C.; ALMEIDA, A. C. S.; GEISENHOFF, L. O.; LIMA JUNIOR, J. A.; NIZ, A. I. S. Effects of top-dressing nitrogen levels on the productivity of cauliflower. Científica, Jaboticabal, v.45, n.2, p.190-196, 2017. Disponível em: < http://dx.doi.org/10.15361/1984-5529.2017v45n2p190-196. 190>. Doi: 10.15361/1984-5529.2017v45n2p190-196.

PIZETTA, L.C.; FERREIRA, M.E.; CRUZ, M.C.P.; BARBOSA, J.C. Resposta de brócolis, couve-flor e repolho à adubação com boro em solo arenoso. Horticultura Brasileira, Brasília, v.23, n.1, p.51-56, jan-mar. 2005. Disponível em: < http://dx.doi.org/10.1590/S0102-05362005000100011>. Doi: http://dx.doi.org/10.1590/S0102-05362005000100011.

SILVA, K. S.; SANTOS, E. C. M.; BENETT, C. G. S.; LARANJEIRA, L.T.; EBERHARDT NETO, E.; COSTA, E. Produtividade e desenvolvimento de cultivares de repolho em função de doses de boro. Horticultura Brasileira 30: 520-525, 2012. Disponível em: < http://dx.doi.org/10.1590/S0102-05362012000300027>. Doi: 10.1590/S0102-05362012000300027.

SILVA, L. M.; BASÍLIO S. A.; SILVA JÚNIOR, R. L.; NASCIMENTO, M. V.; BENETT, C. G. S.; BENETT, K. S. S. Aplicação de ácido bórico sobre as características produtivas do repolho em diferentes épocas. Revista de Agricultura Neotropical, Cassilândia-MS, v. 1, n. 2, p. 26-34, out./dez. 2014. Disponível em: http://periodicosonline.uems.br/index.php/agrineo/article/view/228.

TORRES, J. L. R.; ARAÚJO, A. S.; SILVA NETO, O. F.; SILVA, V. R.; FERREIRA, E. G. G.; VIEIRA, D. M. S. Avaliação agronômica da couve-flor e rabanete cultivados em sucessão a diferentes coberturas. Enciclopédia Biosfera, Centro Científico Conhecer - Goiânia, v.10, n.18; p. 602, $2014 a$. 
TORRES, J. L. R.; VALLE, D. X. P.; CUNHA, M. A. Aspectos morfológicos e produtividade da cultivar Sharon de couve-flor cultivada em diferentes solos. Magistra, Cruz das Almas - BA, V. 26, n. 2, p. 123-131, Abr./Jun. 2014b. Disponível em: < https://www.researchgate.net/publication/269396292>.

TORRES, J. L. R.; ARAÚJO, A. S.; BARRETO, A. C.; SILVA NETO, O. F.; SILVA, V. R.; VIEIRA, D. M. S. Desenvolvimento e produtividade de couve-flor e repolho influenciados por tipos de cobertura do solo. Horticultura Brasileira 33: 510-514. 2015. Disponível em: < http://dx.doi.org/10.1590/S0102-053620150000400017>. Doi: 10.1590/S0102-053620150000400017.

ZANUZO, M. R.; RIBEIRO, L. M.; LANGE A.; MACHADO, R. A. F.; MASSAROTO, J, A. Desempenho agronômico de genótipos de couve-flor nas condições edafoclimáticas de Sinop. Horticultura Brasileira 31: 332-337, 2013. Disponível em: < http://dx.doi.org/10.1590/S0102-05362013000200026>

Doi: 10.1590/S0102-05362013000200026. 